\title{
Indoor environmental risk factors in young asthmatics: a case-control study
}

\author{
A Lindfors, $M$ Wickman, G Hedlin, G Pershagen, H Rietz, S L Nordvall
}

\begin{abstract}
One hundred and ninety three children with asthma and 318 controls aged 1-4 years were evaluated for atopic heredity and exposure to possible indoor risk factors for asthma - for example exposure to furred pets, tobacco smoke, and home dampness. A subgroup of cases were classified as cat and/or dog allergic on the basis of skin prick tests.

Heredity for asthma was a significant risk factor (odds ratio (OR) 3.0, confidence interval (CI) $2 \cdot 1$ to $4 \cdot 6$ ). Environmental tobacco smoke was associated with an excess risk for asthma (OR 1.7, CI 1.1 to 2.3) and signs of home dampness tended to increase this risk (OR 1.3, CI 0.9 to $2 \cdot 0)$. High dose exposure to cat and/or dog resulted in an increased risk only in asthma cases sensitised to cat and/or dog (OR $2 \cdot 7$, CI 1.0 to $7 \cdot 3$ ). A combination of high dose exposure to cat and/or dog, environmental tobacco smoke and damp housing was associated with an OR of 8.0 (CI 1.9 to $34 \cdot 1$ ). Raised indoor humidity has been shown to reflect low air exchange, which may also lead to increased doses of inhaled aeroallergens and tobacco smoke, and contribute to the interaction between the three risk factors.

(Arch Dis Child 1995; 73: 408-412)
\end{abstract}

Keywords: asthma, indoor risk factors, cat.

In the last decades a considerable increase in the prevalence of atopic disease in childhood and adolescence has been reported in the western world. ${ }^{1-5}$ Considerable environmental changes have also taken place during this period. For instance, pollution from motor vehicle has increased outdoors and energy saving measures, undertaken particularly in temperate areas, may have changed the indoor climate. A large number of studies confirm environmental influences on the development of atopic disease, ${ }^{6-13}$ but interactions between risk factors have only been investigated to a limited extent. ${ }^{12}$

Exposure to inhalant allergens and pollutants influence the development and prognosis of wheezing and asthma in childhood ${ }^{14-16}$ and allergen exposure during the first few years of life appears particularly important for atopic sensitisation and induction of atopic disease. ${ }^{17-21}$ It has even been claimed that increased sensitisation to inhaled allergens is the most probable explanation for the increased prevalence of asthma. ${ }^{22}$ Among air pollutants environmental tobacco smoke seems especially detrimental during this first vulnerable period of life. ${ }^{23} 24$

The aim of the present study was to analyse the importance of exposure in early childhood to various indoor environmental risk factors for the development of bronchial asthma in young children. Particular emphasis was put on exposure to furred pets and interactions between risk factors.

\section{Patients and methods}

STUDY SUBJECTS

A case-control study in children 1 to 4 years of age was conducted in the catchment areas of three of four major Stockholm hospitals, Danderyd, Huddinge, and St Göran. The areas are mainly urban and suburban. All the hospitals have paediatric departments with wards and emergency units as well as an outpatient allergy clinic, which serves as a referral unit for children with atopic disorders. Admissions of children due to acute asthma in the catchment areas occur almost exclusively to the paediatric wards of these hospitals.

The case group included 193 children 12-48 months old who had been referred to the specialist allergy clinics of the three hospitals for evaluation of bronchial asthma between May 1990 and March 1992. On the basis of the result of skin prick tests (see below) the cases were subclassified either as cat and/or dog allergen positive (CDP, $n=34$ ) or negative (CDN, $n=159)$. Sixty nine per cent of the children were below 30 months of age at inclusion. Only children with three or more episodes of airway obstruction with asthmatic symptoms such as wheezing, cough, etc, were included, but the symptoms were generally more severe than indicated by this minimal inclusion criterion. The main reason for referral was one or several hospital admissions $(n=122)$ or emergency visits $(n=58)$ for asthma symptoms. Another 13 children had been referred from other physicians after repeated acute episodes of wheezing.

The parents were given written information about the study and an appointment for an initial visit to a nurse was given. Participation was refused for five children. Skin prick tests were performed at the visit with aqueous extracts of egg white, Dermatophagoides pteronyssinus, cat, dog, rabbit, horse, birch, and timothy (Soluprick $10 \mathrm{HEP}, \mathrm{ALK}$, Hörsholm, Denmark). Extracts of the same batch were used in all three hospitals. Histamine hydrochloride $10 \mathrm{mg} / \mathrm{ml}$ and saline were used as positive and negative controls. The control tests and those with cat and dog allergen extracts were performed in duplicate. The test 
Table 1 Hereditary risk factors in children with asthma not sensitised to cat and/or dog (CDN group) or with such sensitisation (CDP group)

\begin{tabular}{|c|c|c|c|c|c|c|c|}
\hline & \multirow{2}{*}{$\begin{array}{l}\text { Control } \\
\text { group } \\
(n=318)\end{array}$} & \multirow{2}{*}{$\begin{array}{l}C D N \\
\text { group } \\
(n=159)\end{array}$} & \multirow{2}{*}{$\begin{array}{l}C D P \\
\text { group } \\
(n=34)\end{array}$} & \multicolumn{2}{|c|}{$\begin{array}{l}\text { CDN group v } \\
\text { control group }\end{array}$} & \multicolumn{2}{|c|}{$\begin{array}{l}C D P \text { group } \mathrm{v} \\
\text { control group }\end{array}$} \\
\hline & & & & $O R$ & $C I$ & $O R$ & $C I$ \\
\hline \multicolumn{8}{|l|}{ Asthma } \\
\hline Maternal & 25 & 34 & 6 & $3 \cdot 2$ & 1.8 to 5.5 & $2 \cdot 5$ & 1.0 to 6.5 \\
\hline Paternal & 28 & 30 & 8 & $2 \cdot 4$ & 1.4 to 4.2 & $3 \cdot 2$ & 1.3 to $7 \cdot 6$ \\
\hline Parental & 51 & 60 & 11 & $3 \cdot 2$ & 2.0 to 4.9 & 2.5 & 1.2 to $5 \cdot 4$ \\
\hline \multicolumn{8}{|c|}{ Rhinoconjunctivitis } \\
\hline Maternal & 87 & 60 & 11 & 1.6 & $1 \cdot 1$ to $2 \cdot 4$ & $1 \cdot 3$ & 0.6 to 2.7 \\
\hline Paternal & 71 & 65 & 15 & $2 \cdot 4$ & 1.6 to 3.6 & $2 \cdot 7$ & 1.3 to 5.6 \\
\hline Parental & 135 & 101 & 19 & $2 \cdot 4$ & 1.6 to 3.5 & $1 \cdot 7$ & 0.9 to 3.5 \\
\hline \multicolumn{8}{|c|}{ Atopic eczema } \\
\hline Maternal & 70 & 44 & 11 & $1 \cdot 4$ & 0.9 to 2.1 & $1 \cdot 7$ & 0.8 to 3.6 \\
\hline Paternal & 40 & 25 & 8 & $1 \cdot 3$ & 0.8 to $2 \cdot 2$ & $2 \cdot 1$ & 0.9 to 5.0 \\
\hline Parental & 95 & 64 & 16 & 1.6 & 1.1 to 2.4 & $2 \cdot 1$ & 1.0 to $4 \cdot 3$ \\
\hline
\end{tabular}

was considered positive if the weal diameter was at least $3 \mathrm{~mm}$ in a single or one of the duplicate tests. At a later visit to a paediatric allergologist a structured clinical evaluation was performed, which included a final evaluation of compliance with the inclusion criteria. At this visit the treatment and medical handling of the patient was revised and a standardised written instruction about allergen avoidance measures was handed out.

Four hundred children were randomly selected from the population of the hospital catchment areas to serve as controls, after matching with the cases for time of birth in intervals of half a year. The parents of nine children could not be located and one control had fulfilled the case criteria before the time of the study and was excluded.

The controls were selected in the later part of the study period, after identification of the cases, and their age was about nine months higher in average, at the time of inclusion. The response rate was $82 \%(n=318)$ and $99(31 \%)$ were below 30 months of age.

\section{QUESTIONNAIRE}

A questionnaire was sent to the parents of the children under study. It focused on heredity, atopic symptoms, and on various indoor environmental conditions on the children's homes. Heredity for atopic diseases was defined by the occurrence of atopic disease in one or both of the parents.

Questionnaire information was also obtained about parental tobacco smoking during pregnancy and after the child's birth. Exposure to environmental tobacco smoke was defined as any period of regular parental smoking in the home during the child's first two years of life. Window pane condensation in the bedroom or living room during the winter was used as a marker of home dampness. ${ }^{25} 26$

Special emphasis was put on direct and indirect exposure to fur coated animals, particularly to cat and dog. Using the questionnaire data, exposure to cat and/or dog during the first two years of life was classified into three different categories: 'High dose exposure': cat and/or dog in the current and/or previous home or nursery of the child, or any other home where the child had lived for more than three days monthly; 'low dose exposure': direct contact up to three days a month or indirect exposure to such animals, for example in the homes of friends, neighbours, summerhouse, or other locations regularly visited by family members; and 'no exposure': no obvious direct or regular indirect contacts with cat and/or dog.

\section{STATISTICAL ANALYSES}

Risks associated with various exposures were expressed as the odds ratio (OR) calculated using the Mantel-Haenszel procedure with maximum likelihood method estimates of the $95 \%$ confidence interval (CI). ${ }^{27}$ Tests for trend were performed according to the method proposed by Mantel, using two tailed p values. ${ }^{28}$ In some analyses adjustments were made for age (more or less than 30 months), sex and parental asthma, which were significant risk factors for asthma. However, this did not have a marked effect on the results, indicating that there was no confounding, and the data are presented without adjustments.

This study was approved by the ethical committee of the Karolinska Institute, Stockholm, Sweden.

\section{Results}

There were significantly more boys in the case group (75\%) (OR 3.0 , CI 2.0 to 4.4 ) and parental divorce was more common among cases then among controls (OR 1.9 , CI 1.0 to 3.6).

Thirty four cases were skin prick test positive to cat and/or dog and constituted the CDP group; of these children 29 were skin prick test positive to cat and 20 to dog. The remaining 159 cases constituted the CDN group. Fifteen children were skin prick test positive to horse and 11 to rabbit; all but six of these children

Table 2 Housing conditions in children with asthma not sensitised to cat and/or dog (CDN group) or with such sensitisation (CDP group)

\begin{tabular}{|c|c|c|c|c|c|c|c|}
\hline & \multirow{2}{*}{$\begin{array}{l}\text { Control } \\
\text { group } \\
(n=318)\end{array}$} & \multirow{2}{*}{$\begin{array}{l}C D N \\
\text { group } \\
(n=159)\end{array}$} & \multirow{2}{*}{$\begin{array}{l}\text { CDP } \\
\text { group } \\
(n=34)\end{array}$} & \multicolumn{2}{|c|}{$\begin{array}{l}C D N \text { group } \mathrm{v} \\
\text { control group }\end{array}$} & \multicolumn{2}{|c|}{$\begin{array}{l}\text { CDP group } \mathrm{v} \\
\text { control group }\end{array}$} \\
\hline & & & & $O R$ & $C I$ & $O R$ & $C I$ \\
\hline $\begin{array}{l}\text { Apartment house } \\
\text { Residence area }<21 \mathrm{~m}^{2} / \text { inhabitant } \\
\text { Window pane condensation } \\
\text { Damage due to dampness } \\
\text { Visible mould } \\
\text { Fitted carpets }>10 \mathrm{~m}^{2} \\
\text { Allergen avoidance measures } \\
\text { Vacuum cleaning }>3 \text { times/week }\end{array}$ & $\begin{array}{r}139 \\
58 \\
70 \\
54 \\
44 \\
67 \\
27 \\
74\end{array}$ & $\begin{array}{l}81 \\
37 \\
41 \\
33 \\
27 \\
19 \\
52 \\
52\end{array}$ & $\begin{array}{r}18 \\
6 \\
12 \\
5 \\
4 \\
3 \\
15 \\
11\end{array}$ & $\begin{array}{l}1 \cdot 3 \\
1 \cdot 4 \\
1 \cdot 3 \\
1 \cdot 3 \\
1 \cdot 3 \\
0 \cdot 6 \\
5 \cdot 2 \\
1.6\end{array}$ & $\begin{array}{l}0.9 \text { to } 2 \cdot 0 \\
0.9 \text { to } 2 \cdot 2 \\
0.8 \text { to } 2 \cdot 0 \\
0.8 \text { to } 2 \cdot 0 \\
0.7 \text { to } 2 \cdot 2 \\
0.3 \text { to } 1 \cdot 1 \\
3.1 \text { to } 8 \cdot 6 \\
1.1 \text { to } 2 \cdot 4\end{array}$ & $\begin{array}{l}1.4 \\
1.0 \\
1.9 \\
0 \cdot 8 \\
0 \cdot 8 \\
0 \cdot 4 \\
8 \cdot 5 \\
1.6\end{array}$ & $\begin{array}{l}0.7 \text { to } 2.9 \\
0.4 \text { to } 2.4 \\
0.9 \text { to } 4.3 \\
0.3 \text { to } 2.4 \\
0.2 \text { to } 2.6 \\
0.1 \text { to } 1.5 \\
6.3 \text { to } 11.5 \\
0.8 \text { to } 3.3\end{array}$ \\
\hline
\end{tabular}

*Removal of fitted carpets, unsuitable bedding, flowers and/or pets, measures to handle dampness problems and/or avoidance of indoor smoking. 
Table 3 Exposure to cat and dog during the first two years of life in children with asthma not sensitised to cat and/or dog (CDN group) or with such sensitisation (CDP group)

\begin{tabular}{|c|c|c|c|c|c|c|c|c|}
\hline & \multirow{2}{*}{$\begin{array}{l}\text { Control } \\
\text { group } \\
(n=318)\end{array}$} & \multirow{2}{*}{$\begin{array}{l}\text { CDN } \\
\text { group } \\
(n=159)\end{array}$} & \multirow{2}{*}{\multicolumn{2}{|c|}{$\begin{array}{l}\text { CDP } \\
\text { group } \\
(n=34)\end{array}$}} & \multicolumn{2}{|c|}{$\begin{array}{l}\text { CDN group v } \\
\text { control group }\end{array}$} & \multicolumn{2}{|c|}{$\begin{array}{l}C D P \text { group } \mathrm{v} \\
\text { control group }\end{array}$} \\
\hline & & & & & $O R$ & $C I$ & $O R$ & $C I$ \\
\hline \multicolumn{9}{|l|}{ Cat } \\
\hline \multirow{3}{*}{$\begin{array}{l}\text { High dose } \\
\text { Low dose } \\
\text { No dose }\end{array}$} & \multirow{3}{*}{$\begin{array}{r}71 \\
108 \\
139\end{array}$} & \multirow{3}{*}{$\begin{array}{l}30 \\
49 \\
80\end{array}$} & \multirow{3}{*}{$\begin{array}{r}14 \\
11 \\
9\end{array}$} & & $\begin{array}{l}0.7 \\
0.8\end{array}$ & 0.4 to 1.2 & $\begin{array}{l}3.0 \\
1.6\end{array}$ & 1.3 to $7 \cdot 2$ \\
\hline & & & & & & & & \\
\hline & & & & Trend & $p=0$ & & $\mathrm{p}=0$ & \\
\hline \multirow{3}{*}{$\begin{array}{l}\text { Dog } \\
\text { High dose } \\
\text { Low dose } \\
\text { No dose }\end{array}$} & \multirow{3}{*}{$\begin{array}{r}51 \\
117 \\
150\end{array}$} & \multirow{3}{*}{$\begin{array}{l}20 \\
61 \\
78\end{array}$} & \multirow{3}{*}{$\begin{array}{r}8 \\
14 \\
12\end{array}$} & & 0.8 & 0.4 to 1.4 & $2 \cdot 0$ & 0.8 to 4.9 \\
\hline & & & & & $1 \cdot 0$ & 0.7 to 1.5 & $1 \cdot 5$ & 0.7 to 3.3 \\
\hline & & & & Trend & $p=0$ & & $\mathrm{p}=0$ & \\
\hline \multirow{4}{*}{$\begin{array}{l}\text { Cat/dog } \\
\text { High dose } \\
\text { Low dose } \\
\text { No dose }\end{array}$} & & & & & & & & \\
\hline & \multirow{3}{*}{$\begin{array}{r}105 \\
134 \\
79\end{array}$} & \multirow{3}{*}{$\begin{array}{l}46 \\
64 \\
49\end{array}$} & \multirow{3}{*}{$\begin{array}{r}18 \\
11 \\
5\end{array}$} & & 0.7 & 0.4 to 1.2 & $2 \cdot 7$ & 1.0 to 7.3 \\
\hline & & & & & 0.8 & 0.5 & 1.3 & 0.5 \\
\hline & & & & Trend & $p=0$ & & $\mathrm{p}=0$ & \\
\hline
\end{tabular}

were positive to cat and/or dog. Eight children were positive to mite, 20 to birch, and four to timothy, while 20 cases were skin prick test positive to egg white.

Heredity for atopic diseases was more prevalent among cases than controls (table 1). The difference was found for all diseases under study, but appeared more prominent for parental airway disease than dermatitis. The influence of parental asthma was particularly strong. Thus, more than $20 \%$ of the parents of the case group children reported bronchial asthma compared with $8 \%$ of those in the control group.

Duration of breast feeding and the age for introduction of common allergenic foods in the children's diet did not differ markedly between cases and controls. Thus cows' milk had been introduced before 3 months' age in $44 \%$ of the case group children, compared with $38 \%$ of the controls. Dietary manipulations, that is reduction of maternal intake of allergenic foods during pregnancy, lactation, and/or delay of introduction of such food to the child during infancy, had been undertaken by similar proportions of cases $(17 \%)$ and controls (15\%).

Residential characteristics are given in table 2. No major differences were seen between cases and controls or between the two case groups in the occurrence of most residential factors. However, window pane condensation tended to be most frequent in the CDP group (OR 1.9 , CI 0.9 to 4.3 ). Allergen avoidance measures during the last two years, that is removal of fitted carpets and unsuitable beddings, measures to control dampness problems, avoidance of indoor smoking, removal of pets and flowers, and frequent ( $>3$ times/ week) vacuum cleaning, were more common in the homes of the cases than of the controls.

Table 4 Interaction between parental smoking, window pane condensation and exposure to cat and/or dog in children with asthma not sensitised to cat and/or dog (CDN group) or with such sensitisation (CDP group)

\begin{tabular}{|c|c|c|c|c|c|c|c|}
\hline \multirow{2}{*}{$\begin{array}{l}\text { No of risk } \\
\text { factors }\end{array}$} & \multirow{2}{*}{$\begin{array}{l}\text { Control } \\
\text { group } \\
(n=318)\end{array}$} & \multirow{2}{*}{$\begin{array}{l}C D N \\
\text { group } \\
(n=159)\end{array}$} & \multirow{2}{*}{$\begin{array}{l}C D P \\
\text { group } \\
(n=34)\end{array}$} & \multicolumn{2}{|c|}{$\begin{array}{l}\text { CDN group v } \\
\text { control group }\end{array}$} & \multicolumn{2}{|c|}{$\begin{array}{l}C D P \text { group v } \\
\text { control group }\end{array}$} \\
\hline & & & & $O R$ & $C I$ & $O R$ & $C I$ \\
\hline $\begin{array}{l}\text { None } \\
\text { One } \\
\text { Two } \\
\text { All three }\end{array}$ & $\begin{array}{r}105 \\
127 \\
73 \\
13\end{array}$ & $\begin{array}{r}35 \\
77 \\
37 \\
7\end{array}$ & $\begin{array}{r}6 \\
11 \\
11 \\
6\end{array}$ & $\begin{array}{l}- \\
1.8 \\
1.5 \\
1.6\end{array}$ & $\begin{array}{l}\overline{1} \cdot 1 \text { to } 3.3 \\
0.8 \text { to } 2.7 \\
0.5 \text { to } 4.8\end{array}$ & $\begin{array}{l}- \\
1.5 \\
2 \cdot 6 \\
8 \cdot 0 \\
p<0 \cdot 01\end{array}$ & $\begin{array}{l}- \\
0.5 \text { to } 4.7 \\
0.8 \text { to } 8 \cdot 4 \\
1.9 \text { to } 34 \cdot 1\end{array}$ \\
\hline
\end{tabular}

Residential exposure to environmental tobacco smoke during the first two years of life was a significant risk factor for asthma. Thus, parental smoking was reported in $62 \%$ of the CDP group families (OR $2 \cdot 1$, CI 1.0 to $4 \cdot 2$ ), $55 \%$ of the CDN group families (OR $1 \cdot 6$, CI $1 \cdot 1$ to $2 \cdot 3$ ), and $44 \%$ of the control families. The greatest impact of tobacco smoke was found in the younger age group (below 30 months) both within the CDP group (OR $3 \cdot 6$, CI 1.0 to 13.3 ) and the CDN group (OR 2.1, CI $1 \cdot 2$ to $3 \cdot 7)$. The CDN and CDP groups did not differ significantly in this respect.

High dose exposure to cat and/or dog during the first two years of life was significantly more prevalent in the CDP group children (OR 2.7, CI 1.0 to $7 \cdot 3$ ), but tended to be slightly less prevalent in the CDN group (OR 0.7, CI 0.4 to $1 \cdot 2$ ) in comparison with the control group (table 3). High dose exposure to cat alone was also found more often in the CDP group, compared with the controls (OR 3.0, CI 1.3 to $7 \cdot 2$ ), while the association to dog appeared less pronounced. Significantly more high dose exposure to cat and/or dog was reported for the CDP group when compared with the CDN group (OR $2 \cdot 8$, CI 1.3 to $5 \cdot 8$ ). This was also true for cat alone (OR $3 \cdot 0$, CI 1.4 to 6.6 ), and a tendency was seen for $\operatorname{dog}$ (OR $2 \cdot 1, \mathrm{CI} 0.9$ to $5 \cdot 3)$. The risk of asthma in the CDP group increased with the degree of exposure to cat ( $p$ trend $=0 \cdot 02$ ). The youngest children (below 30 months of age) in the CDP group had been more exposed to cat and/or dog (OR 6.9, CI $2 \cdot 1$ to $22 \cdot 2$ ) as well as to cat (OR $4 \cdot 5, \mathrm{CI} 1 \cdot 5$ to 13.4), and dog (OR 6.2, CI 2.0 to 19.9 ) compared with controls of the same age. A dose related pattern was seen for exposure to cat $(p$ trend $=0.01)$ as well as for $\operatorname{dog}(p$ trend $=0.01)$ in this young age group (not shown in table).

There was a combined effect between environmental tobacco smoke and damp housing in the CDP group and combined exposure to the two risk factors was associated with an OR of $4 \cdot 0, \mathrm{CI} 1 \cdot 6$ to $10 \cdot 5$. No such interaction was found in the CDN group. The combined effect in the CDP group was observed also for exposure to tobacco smoke and high dose of cat/dog (or 3.8 , CI 1.6 to 9.0 ) and to damp housing and high dose of cat/dog (OR 4.4, CI 1.6 to $12 \cdot 0)$. In the CDP group the most pronounced effect (OR $8 \cdot 0$, CI 1.9 to $34 \cdot 1$ ) was observed when all the three risk factors coexisted (table 4). There was a significantly increased risk of asthma in the cat/dog sensitised group with increasing number of risk factors (test for trend $\mathrm{p}<0.001)$. The trend appeared strongest in the CDP group children below 30 months of age (not shown in table).

\section{Discussion}

A main finding in this study is that direct exposure to furred pets during the first few years of life favours the development of sensitisation to furred pets in asthmatic children. The influence of exposure to cat was particularly marked, which fits with several other studies. ${ }^{29-31}$ This may have several reasons. Recent studies indicate that cat allergen may 
remain airborne for long periods of time, ${ }^{32}$ possibly resulting in high inhaled doses of cat allergen. Another contributing factor may be that children's contact with cats are closer than with dogs. ${ }^{33}$ Indirect exposure had little influence on the development of sensitisation to furred pets in asthmatic children in this study, which may be a consequence of the young age of the children. Indirect exposure in homes, at daycare centres and schools, ${ }^{34} 35$ may become more important later in life. A consequence of these results is that exposure to animal pets, cat in particular, should be at focus for primary intervention.

Notably, however, there was no increased overall risk of asthma with the keeping of a cat or dog. This may partly be due to a preponderance of non-atopic forms of asthma in the studied age group obscuring a relationship. Only a subgroup of the asthmatic children developed sensitisation to furred animals, and then particularly when directly exposed in early life. Thus to some extent, sensitisation to cat and/or dog in asthmatic children may be seen as a marker of exposure to these pets during the first years of life. We did not study sensitisation in children without asthma and the relative importance of environmental exposure versus host susceptibility for the observed association is not clear.

Damp housing is of importance for the development of sensitisation to mites, 263637 and living in a damp house has been associated with atopic disease and bronchial hyperreactivity. ${ }^{11} 38$ In a temperate climate, wintertime window pane condensation in bedrooms or living rooms is related to raised indoor humidity, and may be seen as a marker of poor ventilation. ${ }^{25} 26$ In spite of the fact that only few of the children were sensitised to mites, damp housing was associated with childhood asthma, particularly in children sensitised to furred pets. Possibly, the dose of inhaled allergen, cat in particular, may be increased with low indoor air exchange as allergenic particles are kept airborne for a longer period of time in a poorly ventilated dwelling. ${ }^{32}$ This hypothesis is supported by a recent study, where high concentrations of small airborne particles, suggested partly to consist of cat allergen, were found in damp homes. ${ }^{39}$

In a many studies environmental tobacco smoke has been found to be related to development of asthmatic symptoms in children ${ }^{24} 4041$ and our data confirm that the effect is strongest in young children. An effect of tobacco smoke was found both in children with and without sensitisation to cat and/or dog. Enhancement of the risk for atopic sensitisation, for example to animal domestic pets, could be one of the consequences of exposure to environmental tobacco smoke. ${ }^{42}$ Such an effect could explain the interaction between exposure to tobacco smoke and animal pets.

The use of a hospital based material for recruitment of cases involves a risk of selection bias. A bias would be introduced if the referral of cases to allergy specialists was related to some risk factor under study, such as exposure to furred pets. However, exposure to cat and/or dog was of the same magnitude in the case group as in the control group. Only children who were skin test positive to cat and/or dog exhibited a higher reported exposure to these animals during their first two years of life. As no test results were available at the time of referral, it appears unlikely that selection bias could explain this result. Various kinds of recall bias of exposure also deserves attention. For example, there is a risk of underreporting of environmental tobacco smoke among the case group parents, which would rather lead to underestimation of its effects. Allergen avoidance measures particularly in the case families would have the same consequencies. ${ }^{43}$

Window pane condensation and occurrence of residential mould lesions could on the other hand be overreported by the parents of the asthmatic children due to increased awareness of the possible importance of such factors. There was, however, no difference in reported occurrence of mould lesions in the homes of the different groups of children, and overreporting of window pane condensation in the homes of the cases also appears unlikely. Further, it cannot be excluded that there was a higher response rate among control families with atopic diseases, which would contribute to the high prevalence of reported atopy among the controls, and lead to an underestimation of the risk factors under study.

In the present study we found an influence of exposure to environmental tobacco smoke and damp housing on the development of asthma. In the subgroup of cases sensitised to cat and/or dog, exposure to furred pets seemed to be of importance. It was not possible to determine the type of interaction because of small numbers in this group. Allergy to furred domestic pets, cat and dog in particular, is of great importance in asthma all through childhood, and may indicate a poor prognosis of the disease when found in young children. ${ }^{44-46}$

Our findings stress that efforts should be made to help parents to refrain from smoking, improve the ventilation of their homes and reconsider the keeping of fur coated animals. This appears to apply in particular for families with young children and when there is a family history of atopy and asthma.

This study was supported by grants from the Swedish Association against Asthma and Allergy, Konsul TH Bergh's Foundation, and Förenade Liv.

We thank Britta Englundh, Sanna Cadenins, Kerstin Sundell, and Caroline Widlund for excellent assistance.

1 Åberg N. Asthma and allergic rhinitis in swedish conscripts. Clin Exp Allergy 1989; 19: 59-63.

2 Burr ML, Butland BK, King S, Vaughan-Williams E. Changes in asthma prevalence: two surveys 15 years apart. Changes in asthma prevalence: two

3 Haahtela T, Lindholm H, Koskenvuo K, Björksten F. Prevalence in asthma in Finnish young men. BMF 1990; 301: 266-8.

4 Friday G. Morbidity and mortality of asthma. Pediatr Clin North Am 1988; 35: 5

5 Taylor B, Wadsworth $M$, Peckham $C$. Changes in the reported prevalence of childhood eczema since the 1939-1945 war. Lancet 1984; i: 1255-7.

6 Kagamimori S, Katoh T, Naruse Y, et al. The changing prevalence of respiratory symptoms in atopic children in response to air pollution. Clin Allergy 1986; 16: 299-308. Ishizaki T, Koizumi K, Ikemori R, Ishiyama Y, Kushibiki E. Studies of prevalence of Japanese cedar pollinosis among the residents in a densely cultivated area. Ann Allergy 1987; 58: 265-70.

8 Popp W, Zwick H, Steyrer K, Rauscher H, Wanke T. 
Sensitization to aero allergens depends on environmental factors. Allergy 1989; 44: 572-5.

9 Bråbäck L, Kälvesten L. Urban living as a risk factor for atopic sensitization in Swedish schoolchildren. Pediatric Allergy and Immunology 1991; 2: 14-9.

10 Nordvall SL, Eriksson M, Rylander E, Schwartz B. Sensitization of children in the Stockholm area to house dust mite. Acta Paediatr Scand 1988; 77: 716-20.

11 Andrae S, Axelson O, Björksten B, Fredriksson $M$ Kjellman NIM. Symptoms of bronchial hyperreactivity and asthma in relation to environmental factors. Arch Dis and asthma in relation

12 Wickman M, Nordvall SL, Pershagen G. Risk factors in early childhood for sensitization to airborne allergens. Pediatric Allergy and Immunology 1992; 3: 128-33.

13 Warner JO, Price JA. Aero-allergen avoidance in the prevention and treatment of asthma. Clin Exp Allergy 1990; 20 (suppl 3): 15-9.

14 Dold S, Wjst M, von Mutius E, Reitmier P, Stiepel E. Genetic risk for asthma, allergic rhinitis, and atopic dermatitis. Arch Dis Child 1992; 67: 1012-22.

15 Roorda RJ, Gerritsen J, van Aalderen WMC, Knol K Influence of a positive family history and associated allergic diseases on the natural course of asthma. Clin Exp Allergy 1992; 22: 627-34.

16 Rylander E, Pershagen G, Eriksson M, Nordvall L. Parental smoking and other risk factors for wheezing bronchitis in children. Eur f Epidemiol 1993; 9: 517-26.

17 Hattevig G, Kjellman B, Sigurs N, Björksten B, Kjellman NIM. Effect of maternal avoidance of eggs, cow's milk NIM. Effect of maternal avoidance of eggs, cow's milk and fish during lactation upon allergic man

18 Chandra RK, Puri S, Hamed A. Influence of maternal diet during lactation and use of formula feeds on developmen of atopic eczema in high risk infants. $B M F$ 1989; 315: 228-30.

19 Chandra RK, Hamed A. Cumulative incidence of allergic disorders in high-risk infants fed whey hydrolysate, soy and conventional cow milk formulas. Ann Allergy 1991; 67: $129-32$.

20 Arshad SH, Matthews S, Gant C, Hide DW. Effect of allergen avoidance on development of allergic disorders in infancy. Lancet 1992; 339: 1493-7.

21 Holt PG, McNenamin C, Nelson D. Primary sensitization to inhalant allergens during infancy. Pediatric Allergy and to inhalant allergens during

22 Cullinan P, Newman Taylor AJ. Asthma in children: environmental factors. $B M F$ 1994; 308: $1585-6$.

23 Rylander E, Pershagen G, Eriksson M, Nordvall L. Parental smoking and other risk factors for wheezing bronchitis in smoking and other risk factors for wheezing

24 Duff AL, Pomeranz ES, Gelber LE, et al. Risk factors for acute wheezing in infants and children: viruses, passive smoking, and IgE antibodies to inhalant allergens. Pediatrics 1993; 142: 535-40.

25 Wickman M, Emenius G, Egmar L, Axelsson G, Pershagen G. Reduced mite allergen levels in dwellings with mechanical exhaust and supply ventilation. Clin Exp Allergy 1994; 24: 109-14.

26 Wickman M, Nordvall SL, Pershagen G, Sundell J, Schwartz B. House dust mite sensitization in children and residential characteristics in a temperate region. $\mathcal{f}$ Allergy Clin Immunol 1991; 88: 89-95.

27 Robins J, Greenland S, Breslow NE. A general estimator for the variance of the Mantel-Haenszel odds ratio. $A m \mathcal{F}$ Epidemiol 1986; 124: 719-23.

28 Mantel N. Chi-Square test with one degree of freedom: extension of the Mantel-Haenszel procedure. Fournal of the American Statistical Association 1963; 58: 690-700.

29 Murray AB, Fergusson AC. The frequency and severity of cat allergy vs dog allergy in atopic children. $\mathcal{F}$ Allergy Clin Immunol 1983; 72: 145-9.

30 Popp W, Rauscher H, Sertl W, Wanke T, Zwick H. Risk factors for sensitization to furred pets. Allergy 1990; 45: 75-9.

31 Sears MR, Herbison GP, Holdaway MD, Hewitt CJ, Flannery EM, Silva PA. The relative risk of sensitivity to grass pollen, house dust mite and cat dander in the development of childhood asthma. Clin Exp Allergy 1989, 19: 419-24

32 Luczynska CM, Li Y, Chapman MD, Platts-Mills TAE. Airborne concentrations and particle size distribution of allergen derived from domestic cats. Am Rev Respir Dis 1990; 141: 361-7.

33 Murray BA, Ferguson AC, Morrison BJ. The frequency and severity of cat vs dog allergy in atopic children. $f$ Allergy Clin Immunol 1983; 71: 418-22.

34 Munir AKM, Einarsson R, Schou C, Dreborg SKG Allergens in school dust. I. The amount of major cat (Fed $d 1$ ) and dog (Can $f$ ) allergens in dust from Swedish schools is high enough to probably cause perennial schools is high enough to probably cause perennial dog. $₹$ Allergy Clin Immunol 1993; 91: 1067-74.

35 Dybendal $T$, Elsayed. Dust from carpeted and smooth floors. VI. Allergens in homes compared with those in foors. VI. Allergens in homes compared

36 Platt SD, Martin CJ, Hunt SM, Lewis CW. Damp housing mould growth, and symptomatic health state. $B M \mathcal{F} 1988$ 298: 1673-8.

37 Strachan DP. Damp housing and childhood asthma. Validation of reporting of symptoms. $B M \mathcal{F} 1988 ; 297$ 1223-6.

38 Wickman M, Nordvall L, Pershagen G. Risk factors in early childhood for senstization to airborne allergens. Pediatric Allergy and Immunology 1992; 3: 128-33.

39 Munir AKM, Björksten B, Einarsson R, et al. Cat (Fel d1), $\operatorname{dog}($ Can $\mathrm{f} 1$ ), and cockroach allergens in homes of asthmatic children from three climatic zones in Sweden. Allergy 1994; 49: 508-16.

40 Cockcroft D. Cigarette smoking, airway hyperresponsiveness, and asthma. Chest 1988; 94: 675-6.

41 Rylander E, Pershagen G, Eriksson M, Nordvall L. Parental smoking and other risk factors for wheezing bronchitis in smoking and other risk factors for wheezing

42 Ronchetti R, Bonci E, Cutrera R, et al. Enhanced allergic sensitisation related to parental smoking. Arch Dis Child 1992; 67: 496-500.

43 Brunekreef B, Groot B, Hoek G. Pets, allergy and respiratory symptoms in children. Int $\mathcal{f}$ Epidemiol 1992; 2: 338-42.

44 Sporik R, Holgate ST, Cogswell JJ. Natural history of asthma in childhood - a birth cohort study. Arch Dis Child 1991; 66: 1050-3.

45 Foucard T. Allergy and allergy-like symptoms in 1050 medical students. Allergy 1991; 46: 20-6.

46 Croner S, Kjellman NIM. Natural history of bronchia asthma in childhood, a prospective study from birth to 14 years of age. Allergy 1992; 47: 150-7. 